\title{
Penile and scrotal lesions in leprosy: case reports
}

\author{
D A PARIKH*, A C PARIKH† \& R GANAPATI \\ * KEM Hospital, Bombay 400 012; †Bombay Hospital, Bombay 400 \\ 023; †Bombay Leprosy Project, Vidnyan Bhavan, 11 VN Purav \\ Marg Sion-Chunabhatti, Bombay 400 022, India
}

Accepted for publication 26 June 1989

\begin{abstract}
Summary Six leprosy patients in the Ridley-Jopling spectrum of BT-BL showing lesions on penis and scrotum are presented, as we believe that this common enough clinical feature is not well documented in the literature.
\end{abstract}

\section{Introduction}

Groin, perineum along with scalp, axilla and the narrow band of lumbosacral area are considered to be 'immune zones' in leprosy. To the best of our knowledge, clinical involvement of genitals in leprosy has not been well documented in the literature. We report six cases of leprosy, showing involvement of male external genitalia. Lesions on the external genitalia may be encountered in leprosy of all types in the entire Ridley-Jopling spectrum. It is however not known whether lesions due to indeterminate leprosy, representing the earliest clinical manifestation of the disease, can occur in these organs.

\section{Case reports}

We report six cases with leprosy lesions ranging from BT to BL types with clinical photographs (Figures 1 and 2) showing involvement of the penis and the scrotum.

All six patients had borderline leprosy of more than 6 months duration. Three patients had lesions on glans penis. Two cases were in Type 1 lepra reaction. The slit-smear examination was positive in four cases.

\section{Observations and conclusions}

It is known that Mycobacterium leprae has a distinct predilection for the cooler areas of the body. Anish $^{1}$ demonstrated higher temperature of the axilla and scalp as compared to that of the forearm.

Sahni et al. ${ }^{2}$ studied 20 untreated BL and LL cases. They observed groin involvement clinically in five cases, skin-smear positivity in three, while all showed histological changes. Bedi et al. ${ }^{3}$ observed histological involvement of groin in 10 out of 20 LL patients under monotherapy. Pandya 


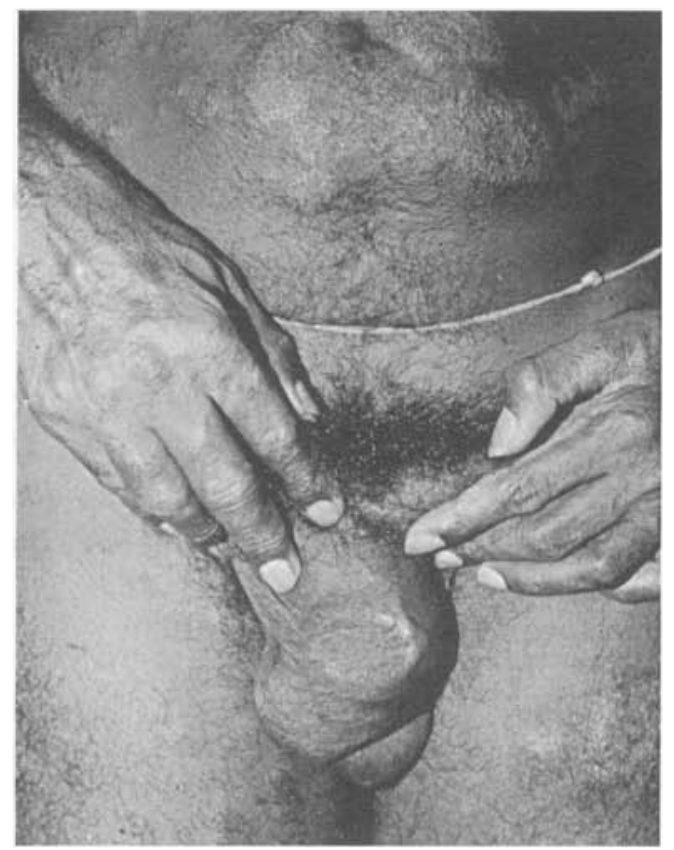

Figure 1. Case No. 2. Erythematous annular lesion on the scrotum.

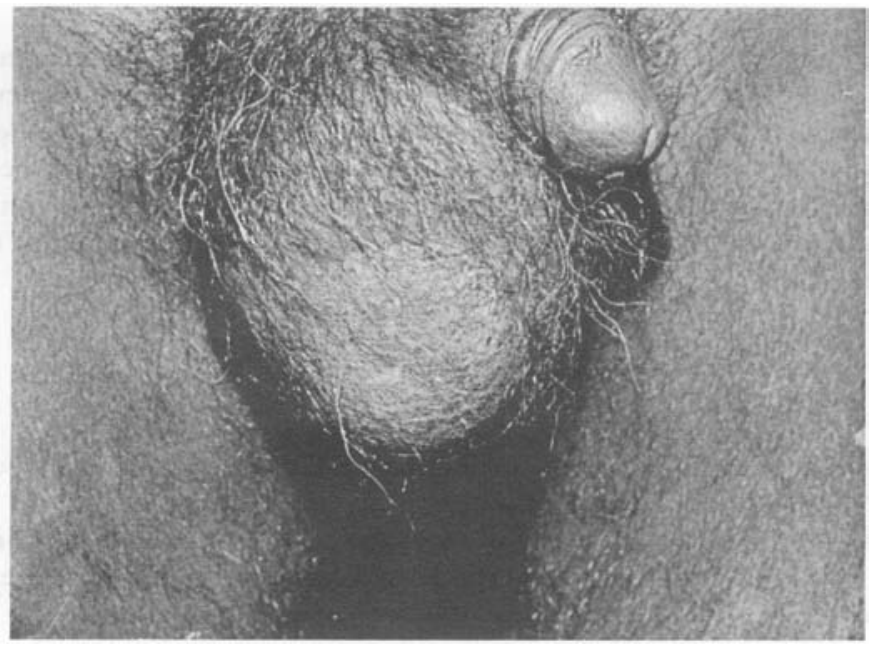

Figure 2. Case No. 6. Hypopigmented dry scaly patch on the scrotum with partial loss of sensation.

\& Antia ${ }^{4}$ studied scrotal skin and underlying dartos biopsies from 45 patients suffering from various types of leprosy (12 TT, 22 borderline \& $11 \mathrm{LL}$ ) most of them treated. In almost all the cases histology showed involvement of the neurovascular bundles. According to them, scrotal skin involvement is due to a liberal supply of larger nerves as compared to cutaneous nerves elsewhere.

If the clinical examination of any male leprosy patient is to be considered exhaustive, it must include examination of external genitalia. 
Table 1

\begin{tabular}{|c|c|c|c|c|}
\hline $\begin{array}{l}\text { Case } \\
\text { No. }\end{array}$ & Age & $\begin{array}{l}\text { Type of } \\
\text { leprosy }\end{array}$ & $\begin{array}{l}\text { Skin-smear } \\
\text { report } \\
\text { for AFB }\end{array}$ & Site of genital involvement \\
\hline 1 & 15 & BT-BB & + & $\begin{array}{l}\text { Erythematous, odematous plaque on } \\
\text { prepuce and shaft of penis. Lesions } \\
\text { are also seen on buttock and thigh. }\end{array}$ \\
\hline 2 & 48 & $\mathrm{BL}$ & + & $\begin{array}{l}\text { Erythematous annular lesion on the } \\
\text { scrotum. Leprosy lesions are also } \\
\text { present on abdomen, thigh and hands. }\end{array}$ \\
\hline 3 & 25 & $\mathrm{BL}$ & + & $\begin{array}{l}\text { Hypopigmented, hypoaesthetic patch } \\
\text { on scrotum extending up to shaft of } \\
\text { the penis. Infiltrated lesions are } \\
\text { seen on thigh. }\end{array}$ \\
\hline 4 & 12 & $\mathrm{BL}$ & + & $\begin{array}{l}\text { Erythematous, oedematous, plaques } \\
\text { on scrotum and prepuce. }\end{array}$ \\
\hline 5 & 25 & BT-BB & $-v e$ & $\begin{array}{l}\text { Small patch on the glans along } \\
\text { with erythematous plaque on the left } \\
\text { thigh. }\end{array}$ \\
\hline 6 & 28 & BT & - ve & $\begin{array}{l}\text { Hypopigmented dry scaly patch on the } \\
\text { scrotum with partial loss of sensation. }\end{array}$ \\
\hline
\end{tabular}

\section{References}

1 Anish SA. The relation between surface temperature and dermal invasion in lepromatous leprosy. Int J Lepr, 1971; 39: 848-51.

2 Sahni U, Reddy BSN, Malik R. Clinicopathology study of so called immune-zones in leprosy; Lepr India, 1982; 54: 256-62.

3 Bedi TR, Kumar B, Kaur S. Histopathological study of clinically normal appearing skin in lepromatous leprosy, Le pr India, 1979; 51: 78-80.

${ }^{4}$ Pandya NJ, Antia NH. The value of scrotal biopsy in leprosy, Lepr Rev, 1974; 45: 145-52. 